IZA DP No. 8309

Loss Aversion in the Laboratory

William Morrison

Robert Oxoby

July 2014 


\title{
Loss Aversion in the Laboratory
}

\author{
William Morrison \\ Wilfrid Laurier University
}

Robert Oxoby

University of Calgary,

CIFAR and IZA

\section{Discussion Paper No. 8309 \\ July 2014}

IZA
P.O. Box 7240
53072 Bonn
Germany

\author{
Phone: +49-228-3894-0 \\ Fax: +49-228-3894-180 \\ E-mail: iza@iza.org
}

\begin{abstract}
Any opinions expressed here are those of the author(s) and not those of IZA. Research published in this series may include views on policy, but the institute itself takes no institutional policy positions. The IZA research network is committed to the IZA Guiding Principles of Research Integrity.

The Institute for the Study of Labor (IZA) in Bonn is a local and virtual international research center and a place of communication between science, politics and business. IZA is an independent nonprofit organization supported by Deutsche Post Foundation. The center is associated with the University of Bonn and offers a stimulating research environment through its international network, workshops and conferences, data service, project support, research visits and doctoral program. IZA engages in (i) original and internationally competitive research in all fields of labor economics, (ii) development of policy concepts, and (iii) dissemination of research results and concepts to the interested public.
\end{abstract}

IZA Discussion Papers often represent preliminary work and are circulated to encourage discussion. Citation of such a paper should account for its provisional character. A revised version may be available directly from the author. 
IZA Discussion Paper No. 8309

July 2014

\section{ABSTRACT}

\section{Loss Aversion in the Laboratory*}

We report the results of a laboratory experiment testing for the existence of loss aversion in a standard risk aversion protocol (Holt and Laury, 2002). In our experiment, participants earn and retain money for a week before using it in an incentivized risk preference elicitation task. We find loss aversion, distinct from risk aversion, has a significant effect on behavior resulting in participants requiring higher compensation to bear risk.

JEL Classification: C91, D91

Keywords: risk aversion, loss aversion, experiments

Corresponding author:

Robert Oxoby

Department of Economics

University of Calgary

2500 University Drive NW

Calgary, Alberta T2N 1N4

Canada

E-mail: oxoby@ucalgary.ca

\footnotetext{
* Support provided by the Social Sciences and Humanities Research Council of Canada is gratefully acknowledged. We wish to thank participants at the 2013 Florence Workshop on Behavioural and Experimental Economics and at the 2013 Canadian Economics Association Meetings in Montreal for comments on a previous working paper based on this research.
} 


\section{Introduction}

Is it possible to measure the influence of loss aversion, separate from risk aversion, in decisions involving risk and intertemporal choice? In this paper we report on an experiment employing a protocol to test for the presence of loss aversion, separate from risk aversion within the well-known risk-preference elicitation framework of Holt and Laury (2002, 2005). Beyond the laboratory, Bowman (1999) and Dimmock and Kouwenberg (2009) have found significant evidence of loss aversion in the manner in which individuals plan consumption streams and in household portfolio decisions. From a policy perspective, Thaler and Bernartzi (2004) and Lusardi (1999) have articulated the importance of taking into account loss aversion and its effects on decision-making in the design of retirement policy and employee savings programs.

In this paper, our objective is to identify and separate the influence of loss aversion from that of risk aversion in decision-making. To this end, we employ a protocol that requires participants to attend two experimental sessions, each one week apart, in which they earn money in the first session to be used in a subsequent session in which risk-preferences are elicited. ${ }^{1}$ Our protocol is designed to avoid a 'found money' bias whereby participants regard money provided by the experimenter as a windfall gain. ${ }^{2} \mathrm{We}$ find that this protocol creates a strong sense of asset legitimacy such that individuals require significantly larger premia (over and above those required as a result of risk aversion) in order to bear risk. This behavior is consistent with loss aversion.

\footnotetext{
1

1 In Morrison and Oxoby (2013) this protocol is used to explore the role of loss aversion in an intertemporal choice setting. See BoschDomenenech and Silvestre (2010) and Rosenboim and Shavbit (2012) for similar protocols that require participants hold on to financial resources for an extended period of time prior to the experiment. .

2 Other researchers have explored the ways in which found money effects and loss aversion can affect decision-making in experiments. For example, Cherry et al (2002) find legitimizing assets significantly reduces contributions in a dictator game. Similarly, Clark (2006) and Harrison (2007) have demonstrated how found money effects can influence decision-making in public goods experiments.
} 


\section{Loss Aversion and Risk Aversion}

The concept of loss aversion (Tversky and Kahneman, 1991; Kahneman, Knetch and Thaler, 1991) posits that an individual will be less willing to agree to a risky prospect if at least one payoff is defined in the domain of losses. Suppose we ask an individual if she is willing to pay $\$ 50$ of her own money to purchase a lottery ticket with a $60 \%$ chance of winning \$150 dollars and a 40\% chance of winning \$0; and suppose that we observe that she chooses not to purchase the lottery. If the decision is due to loss aversion, we infer that she views the lottery outcome of $\$ 0$ as a net loss of $\$ 50$ relative to her reference state income at the time the decision is made. She then assigns a higher (negative) utility to the possible loss of $\$ 50$ than to the prospective net gain of $\$ 100$ if she wins the lottery. However we could also attribute her unwillingness to purchase the lottery ticket as evidence of risk aversion; purchasing the lottery has an expected value of $\$ 70$ but is risky, whereas not purchasing the lottery means retaining \$50 with certainty. How then can we meaningfully separate out the roles played by risk aversion and loss aversion in her decision? In order to separate out these effects, we need to ask her to make another choice that is identical in expected value terms but for which all payoffs lie in the domain of gains. In this version of the decision she chooses between receiving $\$ 50$ with certainty and a lottery ticket with a $60 \%$ chance of winning $\$ 150$ and a $40 \%$ chance of winning $\$ 0$. From a risk perspective, the choice is still between a certain amount and a risky prospect with a known expected value, however there is no role now for loss aversion. Extending this idea, we can ask a series of similar questions in which the expected value of the lottery is increased relative to the certain dollar amount. If the pattern of choice for these decisions is same irrespective of whether payoffs are in the domain of gains or losses, then we can say that loss aversion is not influencing choice. If on the other hand, the individual shows less willingness to choose the lottery when one payoff is defined in the domain of losses, then we have evidence of loss aversion.

Performing a decision experiment as suggested above is easy to construct theoretically, but

poses challenges in experimental design because experimental subjects are typically not 
asked to make incentivized decisions with their own money. To address this, some experimenters attempt to create a sense of ownership over money received by experimental subjects by having individuals earn the money before asking then to make incentivized decisions of interest to the experimenter (see discussions in Harrison et al, 2002, and Harrison et al, 2005). However this may not be sufficient to guarantee that the money earned by subjects has become part of their reference state income, as required by the theory of loss aversion. To address this problem, we ask participants to earn money in an initial laboratory session, and to return one week later to complete an incentivized decision task in which these earnings may be at stake. The intent of the protocol is to place the earned lab dollars firmly within an individual's reference state income so that they regard the money at stake in the decision of interest as their own money.

Our decision follows Holt and Laury $(2002,2005)$, by asking individuals to make a series of choices between ten pairs of lotteries. In each lottery pair, the first lottery (Option A) has a smaller spread relative to the second lottery (Option B). Holt and Laury (HL) hold the dollar amounts constant for each lottery pair but vary the probabilities of winning for each decision to create a scale of increasing expected values. Each successive decision (lottery pair) has higher expected value than the last decision. The defining feature of the HL mechanism is that expected values in early decisions favor Option A while the expected values in later decisions favor Option B. This provides a clear predicted 'crossover point' for risk neutral individuals who should initially prefer Option A and then switch to Option B when its expected value exceeds that of Option A. By extension, those who continue to prefer the safer option (A) beyond the risk neutral cross-over point are displaying risk-averse preferences. In their initial experiment, Holt and Laury find approximately two thirds of participants display risk-averse preferences, even for very small dollar amounts. 


\section{Experiment}

The overall structure of our experiment is illustrated in Figure 1, which shows the order and timing of decisions and payments for a control group and a treatment group of participants.

\section{FIGURE 1: STRUCTURE OF THE EXPERIMENT}

\begin{tabular}{|c|c|c|}
\hline & CONTROL GROUP & TREATMENT GROUP \\
\hline \multirow{8}{*}{ SESSION 1} & COMPLETE QUIZ - EARN \$20 & COMPLETE QUIZ - EARN \$20 \\
\hline & $\downarrow$ & $\downarrow$ \\
\hline & COMPLETE HYPOTHETICAL HOLT-LAURY & COMPLETE HYPOTHETICAL HOLT-LAURY \\
\hline & DECISION TABLE & DECISION TABLE \\
\hline & $\downarrow$ & $\downarrow$ \\
\hline & COMPLETE INCENTIVIZED DECISION TABLE & PAYMENT OF \$20 \\
\hline & 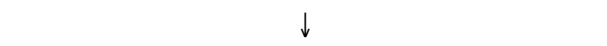 & $\downarrow$ \\
\hline & $\begin{array}{l}\text { CONCLUSION AND FINAL PAYMENT } \\
\text { (INCLUDING \$5 SHOW-UP FEE) }\end{array}$ & 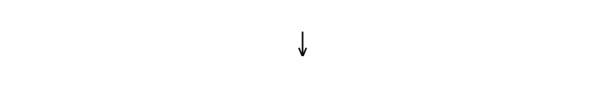 \\
\hline & & $\downarrow$ \\
\hline $\begin{array}{c}\text { SESSION } 2 \\
\text { (one week } \\
\text { after Session 1) }\end{array}$ & & $\begin{array}{c}\text { COMPLETE INCENTIVIZED DECISION TABLE } \\
\downarrow \\
\text { CONCLUSION AND FINAL PAYMENT } \\
\text { (INCLUDING \$5 SHOW UP FEE) }\end{array}$ \\
\hline
\end{tabular}

In order to promote a sense of ownership over the resources to be utilized in the experiment, both groups complete two initial tasks prior to the elicitation of any risk preference information. First, participants take a 20 minute quiz consisting of 20 questions from the Graduate Record Exam (GRE). Participants answering at least 10 questions correctly received \$20; those answering less than 10 questions received $\$ 10$. This threshold was chosen based on previous experiments in order to ensure that all participants would receive \$20 while still requiring participants to exert significant effort.

After completing the quiz, participants complete a hypothetical scaled-up version of the risk preference elicitation decision table in Holt and Laury (2002; Table 1, p. 1645). As shown in Table 1, the expected value of Option A exceeds Option B initially in decisions 
1-4 but has a lower expected value than Option B in decisions 5-10. The purpose of this table is to give an initial, albeit non-incentivized, measure of risk preferences among participants that is comparable between our control and treatment groups.

TABLE 1: HYPOTHETICAL VERSION OF THE HOLT-LAURY DECISION TABLE.

\begin{tabular}{|c|c|c|c|c|c|c|c|c|c|c|c|c|c|c|c|c|c|}
\hline \multirow{2}{*}{\begin{tabular}{|c|} 
Decision \\
1 \\
\end{tabular}} & \multicolumn{8}{|c|}{ Option A Details } & \multicolumn{8}{|c|}{ Option B Details } & \multirow{2}{*}{\begin{tabular}{|c|}
$\begin{array}{l}\text { Difference } \\
\text { in expected } \\
\text { values }\end{array}$ \\
$\$ 116.50$ \\
\end{tabular}} \\
\hline & $A$ & $10 \%$ & chance of & $\$ 200$ & and $a$ & $90 \%$ & chance of & $\$ 160$ & $A$ & $10 \%$ & chance of & $\$ 385$ & and $a$ & $90 \%$ & chance of & $\$ 10$ & \\
\hline & & & & & & & & & & & & & & & & & \\
\hline 2 & A & $20 \%$ & chance of & $\$ 200$ & and $a$ & $80 \%$ & chance of & $\$ 160$ & $\mathrm{~A}$ & $20 \%$ & chance of & $\$ 385$ & and $a$ & $80 \%$ & chance of & $\$ 10$ & $\$ 83.00$ \\
\hline & & & & & & & & & & & & & & & & & \\
\hline 3 & A & $30 \%$ & chance of & $\$ 200$ & and $a$ & $70 \%$ & chance of & $\$ 160$ & $\mathrm{~A}$ & $30 \%$ & chance of & $\$ 385$ & and $a$ & $70 \%$ & chance of & $\$ 10$ & $\$ 49.50$ \\
\hline & & & & & & & & & & & & & & & & & \\
\hline 4 & A & $40 \%$ & chance of & $\$ 200$ & and $a$ & $60 \%$ & chance of & $\$ 160$ & $\mathrm{~A}$ & $40 \%$ & chance of & $\$ 385$ & and $a$ & $60 \%$ & chance of & $\$ 10$ & $\$ 16.00$ \\
\hline & & & & & & & & & & & & & & & & & \\
\hline 5 & A & $50 \%$ & chance of & $\$ 200$ & and $a$ & $50 \%$ & chance of & $\$ 160$ & $\mathrm{~A}$ & $50 \%$ & chance of & $\$ 385$ & and $a$ & $50 \%$ & chance of & $\$ 10$ & $-\$ 17.50$ \\
\hline & & & & & & & & & & & & & & & & & \\
\hline 6 & $\mathrm{~A}$ & $60 \%$ & chance of & $\$ 200$ & and $a$ & $40 \%$ & chance of & $\$ 160$ & $\mathrm{~A}$ & $60 \%$ & chance of & $\$ 385$ & and $a$ & $40 \%$ & chance of & $\$ 10$ & $-\$ 51.00$ \\
\hline & & & & & & & & & & & & & & & & & \\
\hline 7 & $\mathrm{~A}$ & $70 \%$ & chance of & $\$ 200$ & and $a$ & $30 \%$ & chance of & $\$ 160$ & $\mathrm{~A}$ & $70 \%$ & chance of & $\$ 385$ & and $a$ & $30 \%$ & chance of & $\$ 10$ & $-\$ 84.50$ \\
\hline & & & & & & & & & & & & & & & & & \\
\hline 8 & $\mathrm{~A}$ & $80 \%$ & chance of & $\$ 200$ & and $a$ & $20 \%$ & chance of & $\$ 160$ & $\mathrm{~A}$ & $80 \%$ & chance of & $\$ 385$ & and $a$ & $20 \%$ & chance of & $\$ 10$ & $-\$ 118.00$ \\
\hline & & & & & & & & & & & & & & & & & \\
\hline 9 & A & $90 \%$ & chance of & $\$ 200$ & and $a$ & $10 \%$ & chance of & $\$ 160$ & $\mathrm{~A}$ & $90 \%$ & chance of & $\$ 385$ & and $a$ & $10 \%$ & chance of & $\$ 10$ & $-\$ 151.50$ \\
\hline & & & & & & & & & & & & & & & & & \\
\hline 10 & $A$ & $100 \%$ & chance of & $\$ 200$ & and $a$ & $0 \%$ & chance of & $\$ 160$ & $A$ & $100 \%$ & chance of & $\$ 385$ & and $a$ & $0 \%$ & chance of & $\$ 10$ & $-\$ 185.00$ \\
\hline
\end{tabular}

After completing the hypothetical decision table, control group participants complete our incentivized decision table (see Table 2) upon which their remuneration for the experiment is determined. In this decision table, participants are asked to indicate their preference between Option A, which is always \$20 with certainty, or Option B - a lottery in which the high and low payoffs are held constant but the probability of the payoffs change systematically. Participants use the $\$ 20$ they have earned in the quiz for this lottery. That is, if participants chose Option B, they are choosing to give up the $\$ 20$ they had previously earned in the quiz. If participants choose Option A they are opting to retain the $\$ 20$ they had earned in the quiz. Participants are told that one of their ten decisions will be randomly selected and their payment for the experiment will be determined by their answer to the chosen decision. All control group participants are paid in cash at the conclusion of the experiment and receive an additional \$5 show up fee which is independent of any of their decisions. 
TABLE 2: INCENTIVIZED DECISION TABLE.

\begin{tabular}{|c|c|c|c|c|c|c|c|c|c|c|c|}
\hline Decision & Option A & \multicolumn{8}{|c|}{ Option B } & $\begin{array}{c}\text { Option B } \\
\text { Expected } \\
\text { value }\end{array}$ & $\begin{array}{c}\text { Difference } \\
\text { in expected } \\
\text { values }\end{array}$ \\
\hline 1 & $\$ 20.00$ & A & 0.1 & chance of & $\$ 35$ & and a & 0.9 & chance of & $\$ 3.50$ & 6.65 & $\$ 13.35$ \\
\hline 2 & $\$ 20.00$ & A & 0.2 & chance of & $\$ 35$ & and a & 0.8 & chance of & $\$ 3.50$ & 9.80 & $\$ 10.20$ \\
\hline 3 & $\$ 20.00$ & A & 0.3 & chance of & $\$ 35$ & and a & 0.7 & chance of & $\$ 3.50$ & 12.95 & $\$ 7.05$ \\
\hline 4 & $\$ 20.00$ & $A$ & 0.4 & chance of & $\$ 35$ & and a & 0.6 & chance of & $\$ 3.50$ & 16.10 & $\$ 3.90$ \\
\hline 5 & $\$ 20.00$ & $A$ & 0.5 & chance of & $\$ 35$ & and a & 0.5 & chance of & $\$ 3.50$ & 19.25 & $\$ 0.75$ \\
\hline 6 & $\$ 20.00$ & $A$ & 0.6 & chance of & $\$ 35$ & and a & 0.4 & chance of & $\$ 3.50$ & 22.40 & $-\$ 2.40$ \\
\hline 7 & $\$ 20.00$ & $A$ & 0.7 & chance of & $\$ 35$ & and a & 0.3 & chance of & $\$ 3.50$ & 25.55 & $-\$ 5.55$ \\
\hline 8 & $\$ 20.00$ & $A$ & 0.8 & chance of & $\$ 35$ & and a & 0.2 & chance of & $\$ 3.50$ & 28.70 & $-\$ 8.70$ \\
\hline 9 & $\$ 20.00$ & $A$ & 0.9 & chance of & $\$ 35$ & and a & 0.1 & chance of & $\$ 3.50$ & 31.85 & $-\$ 11.85$ \\
\hline 10 & $\$ 20.00$ & A & 1.0 & chance of & $\$ 35$ & and a & $\overline{0 . C}$ & chance of & $\$ 3.50$ & 35.00 & $-\$ 15.00$ \\
\hline
\end{tabular}

Treatment Group participants engage in exactly the same sequence of events, however after taking the GRE quiz, participants are paid in cash and asked to return in one week's time to continue the experiment. Participants are told that they will receive a $\$ 5$ show up fee at the conclusion of session 2 and will have the opportunity to receive additional money. Participants are also told that to participate in session 2, they must bring $\$ 20$ (equal to the amount earned in the first session) with them and that this cash will be used in the experiment.

In the session 2, participants are asked to put \$20 into an envelope labeled with their participant ID and collected by the experimenter. Participants are also asked if the $\$ 20$ cash they put in the envelope in the current session is the same $\$ 20$ they received in session 1 . As our focus is on creating a sense of ownership over the money, this question seeks to identify if participants retain the actual cash from the first session or spend that money and bring their own funds to the current session.

\section{Results}

Fifty-five participants (24 and 36 in each of the control and treatment conditions) were recruited from the undergraduate student body of the University of Calgary using the software developed by Greiner (2004). The experiments were conducted using software 
developed by Fischbacher (2007). All participants (from both treatment and control groups) performed sufficiently well on the GRE quiz to earn \$20. Further all participants in the treatment condition indicated that the \$20 cash they brought to the second session was not the same money they had received in the session 1 (suggesting that money had been spent in the intervening week). ${ }^{3}$

Table 3 provides a summary of our results and Figure 2 presents the percentage of participants (by condition) choosing the less risky option (A) in the hypothetical HL decision table. Similar to the HL experiment, participants display risk-aversion, however, in this hypothetical question, we are unable to reject the hypothesis that participants' answers in the control and treatment groups for each condition are drawn from the same distribution (Wilcoxon $\mathrm{p}>0.4$ ). In other words, participants in the two treatments display similar risk preferences.

TABLE 3: SUMMARY RESULTS

\begin{tabular}{|l|c|c|c|c|}
\hline & \multicolumn{2}{|c|}{ Hypothetical } & \multicolumn{2}{c|}{ Incentivized } \\
& Holt-Laury Decision Task & \multicolumn{2}{c|}{ Decision Task } \\
\hline Group & Control & Treatment & Control & Treatment \\
\hline Average Crossover point & 5.63 & 5.33 & 5.42 & 7.93 \\
\hline Mann-Whitney Test & \multicolumn{2}{|c|}{$\mathrm{P}>0.4$} & \multicolumn{2}{c|}{$\mathrm{P}<0.01$} \\
\hline
\end{tabular}

However, as indicated in Table 3 and illustrated in Figure 3, we find a difference between responses to the incentivized decision table in the control and treatment conditions. Specifically, we can reject the hypothesis that the responses of individuals in the control and treatment conditions are drawn from the same distribution (Wilcoxon $\mathrm{p}<0.01$ ). That is, relative to the control condition, participants in our treatment condition were unwilling to give up the $\$ 20$ in their possession in order to participate in a lottery, even when the lottery offered a high probability of receiving $\$ 35$. This type of behavior is consistent with individuals coding their $\$ 20$ from the previous week as a potential loss in the lottery, and

\footnotetext{
${ }^{3}$ Participants were between the ages of 17 and 26 (average 20.8) and were 55\% male. In an analysis of the data with respect to demographic information we found no gender effect (cf. Coller and Williams, 1999; McLeish and Oxoby, 2007). Three participants in the treatment condition only participated in the first session, yielding an attrition rate of $7.6 \%$.
} 
consequently requiring significantly larger returns to bear the risk of the lottery. This behavior is thus consistent with loss aversion.

FIGURE 2: PERCENTAGE OF PARTICIPANTS CHOOSING THE LESS RISKY OPTION IN HYPOTHETICAL DECISION TABLE

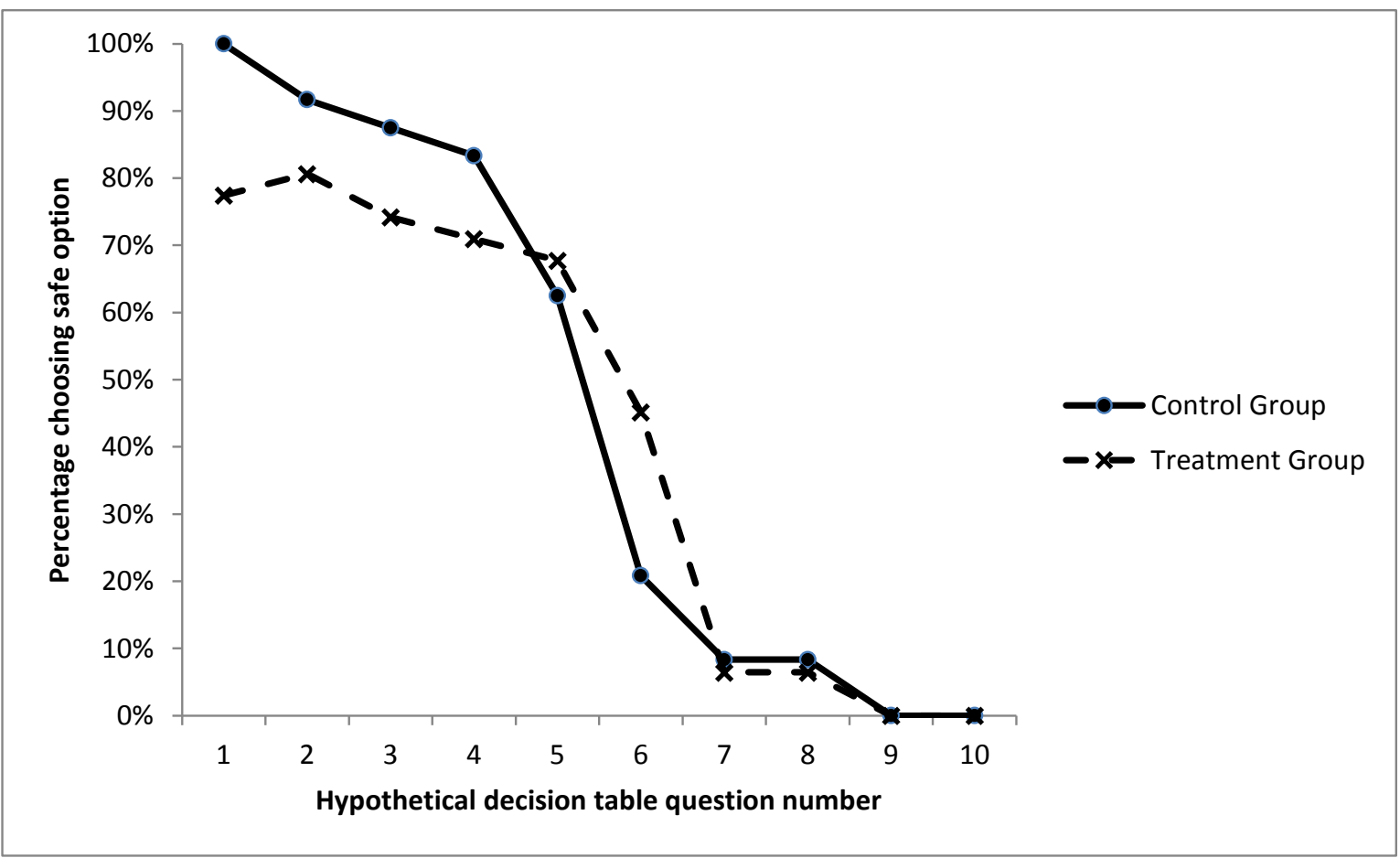

\section{Conclusion}

In this paper, we report on an experiment which explores how a strict sense of asset legitimacy over resources may reveal behavior consistent with loss aversion. Thaler and Bernartzi (2004), Cherry et al (2002), Dimmock and Kouwenberg (2009), and others have demonstrated how asset legitimacy, earnings behavior, and loss aversion can manifest themselves in laboratory experiments. Our experiment contributes to this literature, providing evidence that loss aversion influences decisions involving risk, beyond the effects of risk aversion. This suggests that strategies and public policies designed to 'nudge' individuals to make better decisions in risky environments (e.g., Thaler and Bernartzi, 2004) should account for loss aversion as a significant influence on behavior. Moreover, results of our experiment imply that traditional laboratory and field experiments, in which subjects do not wager their own funds, underestimate the combined effects of loss aversion and risk aversion outside of the laboratory. 
FIGURE 3: PERCENTAGE OF PARTICIPANTS CHOOSING THE SAFE OPTION IN INCENTIVIZED DECISION TABLE.

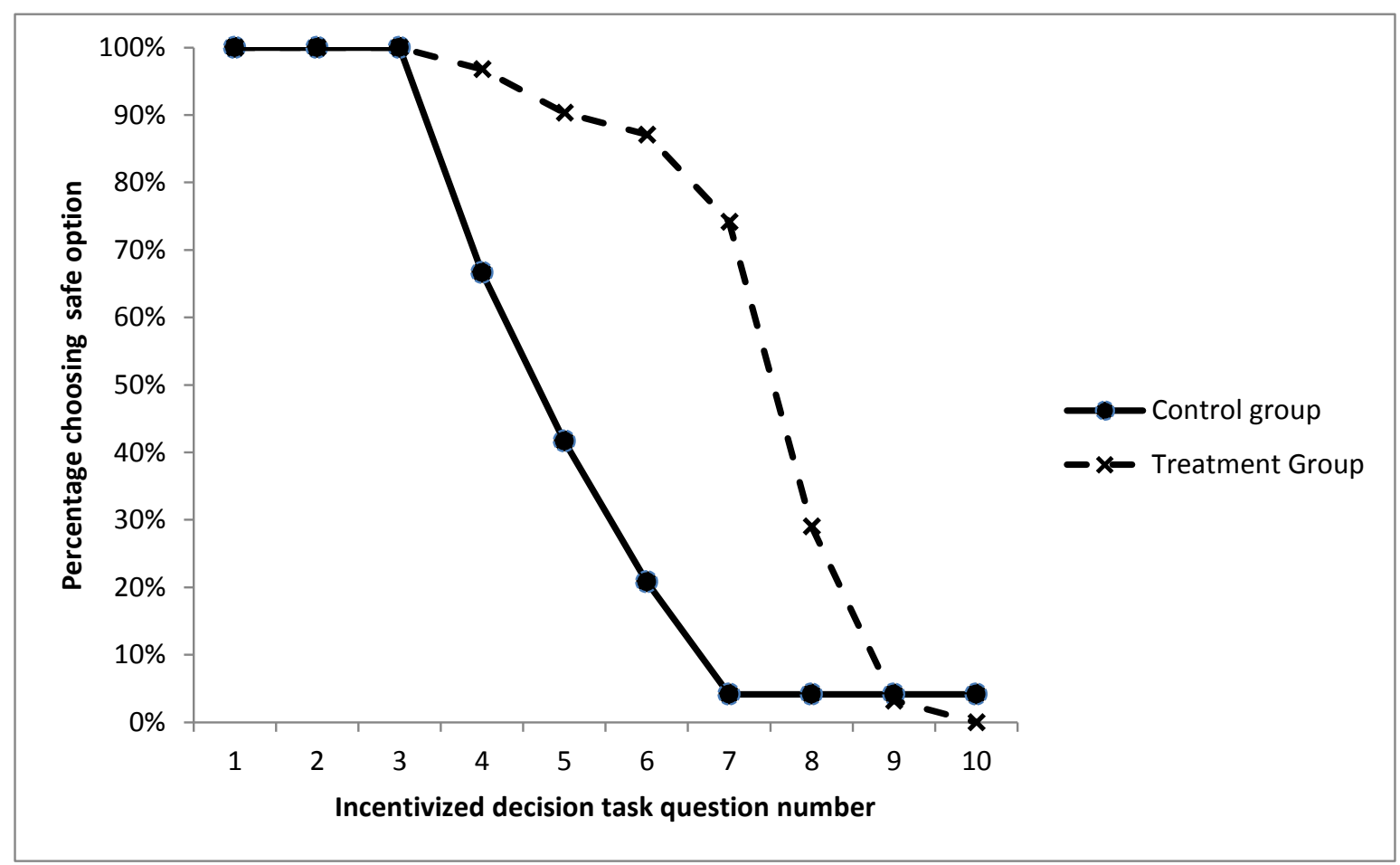

\section{References}

Benartzi, Shlomo, and R. Thaler (1995) "Myopic Loss Aversion and the Equity Premium Puzzle" Quarterly Journal of Economics, 101: 73-92.

Bosch-Domenech, Antoni, and J. Silvestre (2010) "Averting risk in the face of large losses: Bernouli vs. Tversky and Kahneman.” Economic Letters 107, 180-2

Bowman, D., Minehart, D., Rabin, M., 1999. "Loss aversion in a consumption-savings model." Journal of Economic Behavior and Organization 38 (2), 155-78.

Cherry, Todd L., P. Frykblom, and J.F. Shogren (2002) "Hardnose the dictator." American Economic Review 92, 1218-21

Clark, Jeremy (2006) "House money effects in public good experiments." Experimental Economics 5, 223-31.

Coller, Maribeth, and M. B. Williams (1999) "Eliciting Individual Discount Rates." Experimental Economics, 2: 107-127. 
Dimmock, S.G. and R. Kouwenberg, 2009. "Loss-Aversion and Household Portfolio Choice." Journal of Empirical Finance, 17(3): 441-459.

Fischbacher, Urs (2007) "Z-Tree: Zurich toolbox for ready-made economic experiments." Experimental Economics 10(2), 171-178

Greiner, Ben, (2004) " Online Recruitment System ORSEE 2.0 - A Guide for the Organization of Experiments in Economics." Working Paper Series in Economics 10, University of Cologne, Department of Economics.

Harrison, Glenn W. (2007) "House money effects in public good experiments: comment." Experimental Economics 10, 429-37

Harrison, Glenn W., M. Lau, and M.B. Williams (2002) "Eliciting individual discount rates in Denmark: a field experiment." American Economic Review 92, 1606-17

Harrison, Glenn W., M. Lau, E.E. Rutstrom, and M.B. Sullivan (2005) "Eliciting risk and time preferences using field experiments: some methodological issues." Research in Experimental Economics, Vol. 10, ed. J. Carpenter, G. Harrison, and J. List. Greenwich, CT: JAI Press

Holt, C. A. and S. K. Laury (2002). "Risk aversion and incentive effects." American Economic Review, 92(5), 1644-1655.

Holt, C. A. and S. K. Laury (2005). "Risk aversion and incentive effects: New Data without Order Effects." American Economic Review, 95 (3), 902-904.

Kahneman, Daniel, J. L. Knetsch, and R. H. Thaler (1991) "The Endowment Effect, Loss Aversion, and Status Quo Bias.” Journal of Economic Perspectives 5 (1): 193-206.

Kahneman, Daniel and A. Tversky (1979) "Prospect Theory: An Analysis of Decision Under Risk," Econometrical 47: 263-291.

McLeish, Kendra N., and R. J. Oxoby (2007) “Gender, affect and intertemporal consistency: An experimental approach.” IZA working paper 2663.

Morrison, W. and R. Oxoby (2013). “: The endowment effect and intertemporal choice: A laboratory experiment." Canadian Journal of Economics 46 (2).

Rosenboim, M. and T. Shavit (2012), "Whose Money is it Anyway? Using Prepaid Incentives in Experimental Economics to Create a Natural Environment," Experimental Economics 15: 145-157. 